\title{
FORMAÇÃO CONTINUADA CENTRADA NA ESCOLA
}

\author{
Fátima Santa Fé Borges ${ }^{1}$ \\ Ohttps://orcid.org/0000-0003-0729-5844
}

Luciana Sedano ${ }^{2}$

Ohttps://orcid.org/0000-0001-7005-3341

Andréa Ribeiro da Silva ${ }^{3}$

Ohttps://orcid.org/0000-0002-9717-8993

Resumo: Neste texto propomos discutir a formação continuada centrada na escola, defendendo o trabalho em parceria com a universidade e investigando quais as possíveis aproximações teóricas com os princípios do Desenvolvimento Profissional Docente. 0 trabalho parte de estudos e reflexões realizados a partir de um projeto de formação com professores (as) de Educação Básica, bem como de um projeto de pesquisa que visa escutar os (as) professores (as) de uma rede municipal de ensino sobre suas concepções acerca das propostas de formação continuada Diante das reflexões realizadas, consideramos a importância da escola enquanto espaço formativo e, como tal, lócus privilegiado para práticas colaborativas de estudos e pesquisas, visto que o (a) professor (a) parte dos seus saberes, experiências e necessidades para planejar e estudar a sua prática, em um exercício organizativo e dinâmico da escola. Destacamos também a importância da parceria na construção desses saberes e na proposição dessa modalidade de formação continuada, no espaço escolar, por contemplar o (a) professor (a) como pesquisador da sua prática docente e em seu local de trabalho, objetivando contemplar a perspectiva de Desenvolvimento Profissional Docente (DPD).

Palavras-chave: formação continuada; desenvolvimento profissional docente; cooperação universidade-escola; formação de professores.

\footnotetext{
${ }^{1}$ Mestranda em Educação da Universidade Estadual de Santa Cruz (UESC) - Ilhéus/BA. Professora da Secretaria Municipal de Educação de Itabuna/BA. E-mail: fatimasfborges@yahoo.com.br.

2 Doutorado em Educação pela Universidade de São Paulo. Professora da Universidade Estadual de Santa Cruz (UESC) - Ilhéus/BA. E-mail: luciana.sedano@gmail.com.

${ }^{3}$ Mestre em Educação pela Universidade Estadual de Santa Cruz (UESC) - Ilhéus/BA. Coordenadora Pedagógica da Secretaria Estadual de Educação da Bahia. E-mail: andreaeadprof@gmail.com.
} 


\section{SCHOOL-FOCUSED CONTINUING EDUCATION}

Abstract: In this text we propose to discuss the continuing education centered in the school, defending the work in partnership with the university and investigating which are the possible theoretical approximations with the principles of Teacher Professional Development. The work is based on studies and reflections carried out from a training project with Basic Education teachers, as well as from a research project that aims to listen to the teachers of a municipal education network about their conceptions about the proposals of continuing education, We consider the importance of the school as a formative space and, as such, a privileged locus for collaborative practices of studies and research, since the teacher starts from his/her knowledge, experiences and needs to plan and study his/her practice, in an organizational and dynamic exercise in the school. We also highlight the importance of the partnership in the construction of this knowledge and in the proposition of this modality of continuing education, in the school space, for contemplating the teacher as a researcher of his/her teaching practice and in his/her workplace, aiming to contemplate the perspective of Teacher Professional Development (PDD).

Keywords: continuing education; teacher professional development; university-school cooperation; teacher education.

\section{FORMACIÓN CONTINUA EN LA ESCUELA}

Resumen: En este texto nos proponemos discutir la formación continua centrada en la escuela, defendiendo el trabajo en colaboración con la universidad e investigando cuáles son las posibles aproximaciones teóricas con los principios del Desarrollo Profesional Docente. El trabajo parte de estudios y reflexiones realizadas a partir de un proyecto de formación con profesores de Educación Básica, así como de un proyecto de investigación que pretende escuchar a los profesores de una red municipal de educación sobre sus concepciones acerca de las propuestas de formación continua, Consideramos la importancia de la escuela como espacio formativo y, como tal, un locus privilegiado para las prácticas colaborativas de estudios e investigación, ya que el profesor parte de sus conocimientos, experiencias y necesidades para planificar y estudiar su práctica, en un ejercicio organizativo y dinámico de la escuela. También destacamos la importancia de la asociación en la construcción de este conocimiento y en la propuesta de esta modalidad de formación continua, en el espacio escolar, para contemplar al profesor como investigador de su práctica docente y en su lugar de trabajo, con el objetivo de contemplar la perspectiva del Desarrollo Profesional Docente (DDP).

Palabras clave: formación continua; desarrollo profesional del profesorado; cooperación universidad-escuela; formación del profesorado. 


\section{Introdução}

0 trabalho docente é amplo e complexo, requer uma organização interna e temporal. E é na escola que o (a) professor (a) desenvolve em sua prática habilidades para planejar e replanejar suas aulas, em rotinas que contemplem planejamentos para seu fazer pedagógico. Nesse sentido, conforme salienta Mizukami (2013), os (as) professores (as) não são inventados por voluntarismos, mas passam por processos formativos, sendo que existem conhecimentos essenciais a esta profissão, como os teóricos específicos da educação, da pedagogia e da didática (GATTI, 2012; LIBÂNEO, 2015) além dos conhecimentos específicos das áreas de conhecimento (CARVALHO; GIL PEREZ, 2011). Ambos os conhecimentos são base para a formação docente, bem como o exercício dessa profissão.

Pensar a organização da prática pedagógica e a docência perpassa por três aspectos principais: a formação de professores (as), inicial e continuada, que pode ser abordada a partir do Desenvolvimento Profissional Docente; da efetivação das políticas públicas educacionais, que visam garantir aos docentes direitos assegurados; e da identidade e valorização profissional. No que diz respeito ao Desenvolvimento Profissional Marcelo García (1999, p. 144), a define como: "Desenvolvimento profissional é um conjunto de processos e estratégias que facilitam a reflexão dos professores sobre a sua própria prática, que contribui para que os professores gerem conhecimento prático, estratégico e consigam aprender com a sua experiência”.

Essa definição de DPD demonstra a importância e a valorização dos conhecimentos que o (a) professor(a) acumula ao longo da sua vida, por meio das suas vivências e que se constitui em um processo contínuo de reflexão da sua prática. São experiências pessoais e coletivas que compreendem o desenvolvimento desse profissional na sua integralidade, visto que o DPD compreende o processo pessoal e profissional do docente.

Desta forma, as discussões sobre formação de professores (as) avançam para um outro patamar, onde a perspectiva de desenvolvimento profissional é considerada, na relação com a prática pedagógica do professor e atuação para a qual é especializado (a), questão importante a ser considerada e que muitas vezes não é atendida, gerando uma inadequação na formação docente e na sua frente de atuação, ou seja, na etapa escolar para qual é designado a atuar (RIBEIRO; SEDANO, 2020). 
Essas considerações vêm acompanhadas de outros elementos culturais, sociais, políticos e econômicos, ou seja, a formação do (a) professor (a) está inserida em um contexto escolar e social, suscetíveis ao contexto social em que está inserido.

Nesta mesma perspectiva, Paulo Freire discute que a educação não é neutra diante das ideologias e nos apresenta as ideologias determinantes que estão presentes na Escola como espaço vital da diversidade de modo a: "Esclarecer a legitimidade do sonho ético-político de superar a realidade injusta [...] trabalhar contra a ideologia fatalista dominante e seu poder de incentivar a imobilidade por parte dos oprimidos e sua adaptação à realidade injusta" (FREIRE, 2004, p. 19). Com base nessa afirmação, o autor destaca a função da visão crítica para a identificação das ideologias determinantes, que muitas vezes estão ocultas, manipulando a realidade e, assim, compreende-se que em consequência, interfere tanto na formação quanto na trajetória docente.

Alguns autores como Imbernón (2002, 2010), Garcia (1999), Marcelo Garcia (2009), Darling-Hammond (2008, 2015), Darling-Hammond, Hyler e Gardner (2017) e Wei et al. (2009) acreditam na formação docente como parte de um desenvolvimento profissional contínuo, que avança durante o percurso profissional, extrapola eventos específicos de aprimoramento por meio de cursos e abarca questões relativas à valorização, remuneração, carreira docente, ambiente de trabalho, estruturas organizacionais, níveis de participação e de decisão.

Assim, se é um percurso contínuo, o Desenvolvimento Profissional Docente tem na formação continuada, uma atividade de extrema importância para promover a aprendizagem profissional, pois se trata de um percurso mais longo e duradouro que a formação inicial, visto que as etapas de formação se complementam e se caracterizam por aspectos relacionados ao tempo de carreira, segmentos de ensino e a docência.

Dessa forma, cientes do papel da formação continuada, Vaillant e Marcelo (2012) listaram algumas premissas básicas que podem favorecer resultados positivos, dependendo do modo como são ajustadas ao contexto em que serão desenvolvidas. Dentre essas premissas, temos: 1 - 0 conteúdo do Desenvolvimento Profissional como determinante para a sua eficácia; 2 - A análise da aprendizagem dos estudantes como eixo articulador; 3 - 0 dever dos docentes de identificar o que precisam aprender; 4 - A escola como lócus de atuação; 5 - A resolução de 
problemas como um aspecto fundamental; 6 - A evolução e continuidade do Desenvolvimento Profissional; 7 - A garantia da incorporação de diferentes fontes de informação; 8 - A necessidade de considerar as crenças como orientadoras de conduta e filtro de conhecimento; 9 - O Desenvolvimento Profissional integrado a um processo de mudança.

As premissas destacadas acima dialogam com a importância da formação continuada, no contexto em que defendemos aqui, a medida em que se pode verificar a oportunidade de aprendizagens para o docente, pois, tais premissas indicam aspectos relevantes ao processo de desenvolvimento profissional que se desenha ao longo da carreira docente, com suas experiências pessoais, profissionais, sua história, construção teórica e aplicação prática dos conhecimentos adquiridos, a partir de experiências formativas individuais ou coletivas, que, acreditamos em diálogo com os autores, a construção trajetória profissional do docente.

Tendo em vista que a escola é o telão de fundo de um processo de mudança onde o eixo articulador é a análise da aprendizagem dos alunos, faz-se necessário que a formação encontre caminhos para potencializar o DPD. Para tanto, abordamos os estudos de Darling-Hammond, Hyler e Gardner (2017) a partir de um levantamento de 35 pesquisas das últimas três décadas em relação à mudança das práticas dos (as) professores (as), que resultaram na melhoria dos resultados dos alunos, e dessa forma, foram levantados elementos predominantes em modelos bem-sucedidos de DPD, o que nos levou a compreender que a potencialidade da formação depende da existência de sete características de eficiência do DPD, a saber: Foco no Conteúdo; Aprendizagem Ativa; Apoio e colaboração em contextos de trabalho; Uso de modelos de prática; Suporte Especializado; Oportunidades de feedback e reflexão; Duração sustentada (DARLING-HAMMOND; HYLER; GARDNER, 2017)

Diante disso, fica evidenciada a importância de a formação ocorrer no espaço escolar, como meio de oportunizar que o conteúdo trabalhado seja oriundo das práticas dos professores (as), a partir de suas demandas pedagógicas, além de ter legitimado o espaço de apoio e colaboração em contextos de trabalho. Além disso, garantir um suporte especializado, e oportunidades de feedback e reflexão em parceria com Instituições de Ensino Superior torna-se imprescindível para o desenho de um Programa de DPD. 
Aliada à importância de uma proposta de formação apoiada nos princípios do DPD, como a institucionalidade que é a formação de professores (as) em parceria com a universidade, em um movimento formativo de escuta às demandas dos (as) professores (as), movimento esse de parceria em que os (as) professores (as) da universidade se colocam à disposição para estudar e aprender com os (as) professores (as) da Educação Básica, em um processo de troca e aproximação teóricoprática, contemplando assim outros princípios do DPD, como: integração, que busca a harmonização da teoria com a prática; a colaboração, o aspecto primordial da formação de professores(as) centrada na escola; gestão de conhecimento, que trata da produção individual e coletiva de conhecimentos entre os pares em seu ambiente de trabalho e fora dele também.

Para além de convidar os (as) professores (as) a assistirem palestras na universidade, o que almejamos, defendemos e realizamos são propostas de formação a médio e longo prazo, preferencialmente, na escola, em parceria com docentes universitários, de acordo com suas linhas de pesquisa e atendendo às demandas formativas apontadas por docentes da Educação Básica de escolas públicas da área de abrangência da Universidade. Desse modo, tende-se a consolidar parceria de crescimento teórico, prático e profissional.

\section{Percurso da Pesquisa}

0 presente texto emerge como demanda reflexiva de uma pesquisa de mestrado que investigou as demandas formativas de Professores da Educação Básica de uma rede municipal do sul da Bahia. Dentre os dados coletados, parte das respostas dos (as) docentes, versavam sobre a importância da formação na escola, com discussões oriundas do cotidiano e cultura escolares.

Dessa feita, surge a necessidade de compor um texto reflexivo, de natureza qualitativa, com base nesses estudos, destacando a importância da Escola enquanto lócus de formação continuada e alinhando a formação continuada aos princípios do Desenvolvimento Profissional Docente.

As discussões aqui apresentadas compõem um debate teórico em defesa da formação centrada na escola, a partir dos estudos e reflexões realizados durante a pesquisa de mestrado. 


\section{A formação continuada de professores (as) centrada na escola}

Para este artigo compreendemos a formação continuada centrada na escola como os momentos de formação em serviço, realizados na própria instituição, onde o (a) docente atua de acordo com suas demandas formativas, inclusive por meio de estudos, leituras, discussões, debates, palestras, reflexões, produções escritas, construção de planos de ensino, de sequências didáticas e de material didático. Todas essas atividades de formação podem ser realizadas em grupo, contando com a força do coletivo e, o mais importante, partindo das demandas reais dos (as) docentes, das necessidades percebidas e vivenciadas em suas salas de aula e trazidas para as situações de estudo.

Defendemos também que essa formação se dê em parceria com a universidade. Em projetos de extensão e pesquisa desenvolvidos pelo nosso grupo de pesquisa (Grupo de Estudos e Pesquisa em Prática Pedagógica e a Docência CNPQ/UESC), temos por objetivo realizar formações nas escolas de Educação Básica conforme as demandas formativas apresentadas pelos (as) professores (as). Enquanto docentes, mestrandos e pesquisadores das áreas de Didática e Ensino de Ciências de uma universidade pública da Região Sul da Bahia, procuramos escolas públicas da área de abrangência da universidade e oferecemos propostas formativas, no espaço físico da escola, com seus profissionais e de acordo com suas demandas de formação, estudo e reflexão.

Compreendemos que, dessa forma, a formação continuada centrada na escola e em parceria com a universidade poderá atender às necessidades pedagógicas do professor (a) e oportunizar novas práticas de formação, por se efetivar em lócus. Segundo Cunha e Prado (2010, p. 102), a formação centrada na escola: “[...] é aquela que acontece no contexto de trabalho, privilegiando a colaboração, a interlocução sobre as práticas, as necessidades e os interesses dos professores que participam da construção e da gestão do plano de formação e são corresponsáveis pelo seu desenvolvimento".

Partindo desse pressuposto, a formação continuada centrada na escola poderá garantir um melhor envolvimento por parte da gestação escolar, sendo que nesse espaço torna maior a possibilidade de toda a equipe diretiva estar presente, 
compartilhando diálogos sobre as práticas educativas desenvolvidas e fortalecendo os vínculos da equipe pedagógica junto aos (às) professores (as).

Ao defendermos a parceria com a universidade, e em conformidade com as pesquisas e projeto de extensão que desenvolvemos (SILVA; SOUZA, 2018) compreendemos que essa parceria é mais uma modalidade de atuação na formação continuada, em uma perspectiva de Desenvolvimento Profissional Docente, sem retirar as demais possibilidades de estudo, discussões, reflexões, e demais possibilidades de formação na escola realizadas pela própria equipe pedagógica em diálogo com as demandas dos(as) professores(as).

Essa modalidade de formação continuada é um desafio que precisa contemplar revisão de referenciais da educação, bem como exigir do (a) professor (a) uma prática reflexiva, inovadora e pautada na cooperação, na diversidade que constitui a sala de aula e a necessidade em manter o estudo e a pesquisa como prática pedagógica e didática. Sendo necessário repensar a formação continuada, partindo da análise das práticas pedagógicas e docentes que se materializa na identidade profissional do (a) professor (a), Pimenta (2002, p. 7) salienta que:

[...] a identidade profissional do professor se constrói a partir da significação social da profissão [...] constrói-se também, pelo significado que cada professor, enquanto ator e autor, confere à atividade docente de situar-se no mundo, de sua história de vida, de suas representações, de seus saberes, de suas angústias e anseios, do sentido que tem em sua vida: o ser professor. Assim, como a partir de sua rede de relações com outros professores, nas escolas, nos sindicatos, e em outros agrupamentos.

Essa significação social da profissão docente propõe revisão constante das práticas consagradas, dos saberes da experiência, saberes da docência e saberes pedagógicos que, segundo Pimenta (1999), conduz ao entendimento da necessidade de o conhecimento refletir na ação, sobre a ação e sobre a reflexão na ação como proposta metodológica para uma identidade necessária de professor (a).

Dessa forma, a modalidade de formação continuada centrada na escola considera a experiência do (a) professor (a) em seu local de trabalho com suas especificidades, próprias do universo escolar, elementos importantes para assegurar a reflexão crítica dos (as) professores (as) com suas práticas e experiências frente a 
sistematização de conhecimentos e saberes construídos no interior da escola. A esse respeito, Gatti (2010, p. 1375) destaca:

\begin{abstract}
No que concerne à formação de professores, é necessária uma verdadeira revolução nas estruturas institucionais formativas e nos currículos da formação. [...] A formação de professores não pode ser pensada a partir das ciências e seus diversos campos disciplinares, como adendo destas áreas, mas a partir da função social própria à escolarização - ensinar às novas gerações o conhecimento acumulado e consolidar valores e práticas coerentes com nossa vida civil.
\end{abstract}

Nessa mesma direção, Azzi (2005) destaca que o saber pedagógico é o saber que o (a) professor (a) constrói no cotidiano do seu trabalho e que fundamenta sua ação docente. Ademais, o saber proporciona ao professor a interação com seus educandos, no contexto da sala de aula. Assim, a Formação continuada centrada na escola atende o atual cenário educacional que exige a presença de profissionais habilitados a desenvolver a sua prática em consonância com a realidade social mais ampla, que tenha consciência da necessidade de articular o processo de ensino e aprendizagem para a formação do educando.

A característica central da práxis é a realidade, e a condição para que a ação seja práxis é a teoria, assim a prática docente é a unidade de ideia e de ação transformadora, que perpassa pelo processo de ensino cotidiano e particularidades do comportamento do (a) professor (a). A construção do conhecimento, a investigação e sistematização com base metódica vem da idealização consciente que busca interferir e transformar a realidade. Nessa perspectiva, Freire (1996) afirma ser deste modo que o momento fundamental da formação permanente de professores (as) deve ser baseado na reflexão sobre a prática de forma crítica. Com isso,

É pensando criticamente a prática hoje ou de ontem que se pode melhorar a próxima prática. 0 próprio discurso teórico, necessário à reflexão crítica. Quanto melhor faça esta operação, tanto mais inteligência ganha da prática em análise e maior comunicabilidade exerce em torno da superação da ingenuidade pela rigorosidade (FREIRE, 1996, p.43-44).

Assim, é na escola, na sala de aula que a ação docente mais aparece e se concretiza, um cotidiano que revela ou encobre a realidade educacional. E o trabalho 
docente exige autonomia pedagógica e formação continuada de professores (a), que estão associados ao processo e movimento de transformação e constituição dos sujeitos. Processo importante para a profissionalização docente, renovação de saberes e mudanças do cotidiano.

A formação nesta perspectiva prioriza as necessidades e expectativas dos professores (as). 0 que implica refletir sobre as práticas pedagógicas, considerando seus locais de trabalho, os contextos sociais e conflitos que necessitam ser superados, ou seja, formação centrada na escola, como um fazer contínuo, priorizando iniciativas que objetivem a renovação de saberes e práticas por meio das transformações promovidas pela formação in loco e assim superar os desafios postos por rotinas dinâmicas.

Nessa composição, o processo de Desenvolvimento Profissional Docente consiste em um compromisso, pessoal e institucional para que a profissionalização possa acontecer, o que depende dos conhecimentos, vivências, saberes, experiências e técnicas que compõe a trajetória do efetivo exercício docente, para a autonomia profissional. Nesse sentido, destacamos Ferreira (2020, p. 5), ao afirmar que “[... não se pode separar o professor daquilo que ele representa; é preciso entendê-lo, bem como o seu processo de desenvolvimento" e, desse modo, compreendemos formação continuada docente centrada na escola, por perpassar "[...] pelo desenvolvimento de uma nova cultura profissional dos professores (as) que passa pela produção de saberes e de valores que deem corpo a um exercício autônomo da profissão docente" (NÓVOA, 1992, p. 26). Assim, a formação continuada centrada na escola possivelmente será rica em sentidos e por estar ligada às experiências dos docentes, pois, a cada dia que passa aumenta as exigências sobre os profissionais da educação no que diz respeito à eficácia do seu trabalho.

\section{Políticas públicas educacionais para formação continuada}

Os elementos de normatização da educação brasileira, Constituição Federal e a Lei de Diretrizes e Bases da Educação - a LDB (BRASIL, 2017) perpassaram por processos políticos, históricos culturais envolvendo diversos interesses, conflitos e desafios. Ainda assim, Gatti (2015, p. 20) considera que a LDB foi "um marco regulatório decisivo para a formação docente nas últimas décadas", pois acompanhou 
uma tendência mundial, determinando que os (as) professores (as) de todos os níveis educacionais tenham formação no Ensino Superior, além de abordar outros aspectos. Assim, as políticas públicas educacionais buscam garantir os direitos previstos em legislação própria, considerando o princípio do direito do indivíduo e assegurando o bem comum. Faz-se necessário destacar as políticas educacionais:

Se constitua em objetivo de políticas que valorizam a formação dos professores não mais baseada na racionalidade técnica, que os considera como meros executores de decisões alheias, mas numa perspectiva que considera sua capacidade de decidir e de, confrontando suas ações cotidianas com as produções teóricas, rever suas práticas e as teorias que as informam, pesquisando a prática e produzindo novos conhecimentos para a teoria e a prática de ensinar (PIMENTA; LIMA, 2004, p. 90-91).

Em 2014, foi aprovado o Plano Nacional de Educação (PNE), que visa direcionar esforços e investimentos para a melhoria da qualidade da educação, estabelecendo diretrizes, metas e estratégias que devem ser atingidas em 10 anos, abrangendo todos os níveis de ensino e modalidades, refere-se à educação inclusiva, indígena, tecnológica, formação profissional, valorização e formação de professores (as) e à distribuição de verbas (BRASIL, 2014).

Diante desse contexto, os municípios construíram seus Planos Municipais de Educação (PME) e assim definiram suas estratégias e períodos para alcançar as metas previstas pelo PNE, fundamental o monitoramento local desse plano por meio dos órgãos de controle social, composto por diversos setores educacionais, públicos, privados e governamentais, no sentido de serem vigilantes da legislação, para a efetivação dessa política pública no período de 10 anos. Esse prazo estabelecido, prorroga e protela ações essenciais para formações de professores e consequentemente para o melhoramento da educação brasileira.

Conforme o documento, a formação continuada de professores (as) poderá ser desenvolvida em diversos espaços que proporcione aos (às) professores (as) momentos de estudo, reflexão e pesquisa sobre a sua prática. Os (as) professores (as) reconhecem que a formação continuada (ou a sua ausência) causa grande impacto na educação brasileira. Assim, busca-se investir nas formações, visto que: 
A discussão sobre a Política Nacional de Formação de Profissionais do Magistério da Educação Básica e o delineamento de um sistema nacional de educação são elementos importantes das políticas federais que impactam diretamente sobre as políticas de formação e profissionalização dos professores em todo o país. Assim, surgem subsídios para o debate sobre a formação inicial e continuada desses profissionais, o trabalho que vem sendo realizado nas instituições formadoras, públicas e privadas, e os currículos dos cursos ofertados (GATTI; BARRETTO; ANDRÉ, 2011, p. 12).

Nessa direção, a publicação da Resolução n.ำ 2, de 1.ำ de julho de 2015, “Define as Diretrizes Curriculares Nacionais para a formação inicial ao nível superior (cursos de licenciatura, cursos de formação pedagógica para graduados e cursos de segunda licenciatura) e para a formação continuada" (BRASIL, 2015). Este documento apresentou mudanças importantes quanto o aumento na carga horária mínima para licenciaturas de 2.800 para 3.200 h, mais tempo para atividades práticas e também da formação pedagógica para graduados não licenciados e segundas licenciaturas.

Contudo, essa resolução foi revogada pela Resolução n. ํㅜ 2, de 20 de dezembro de 2019, que define as Diretrizes Curriculares Nacionais para a Formação Inicial e institui a Base Nacional Comum para a Formação Inicial de Professores da Educação Básica. Essa atual normativa, estranhamente não contempla a formação continuada. Assim, Segundo Freitas (2019), nos esclarece que:

Cada vez mais o professor deverá ter sua formação intrinsecamente ordenada pela BNCC, formulada no interior de uma política de reorientação curricular adotada por vários países, entre eles o Brasil, cujas alianças sociais, políticas e econômicas estão sendo construídas no interior da racionalidade neoliberal na educação, que atende prioritariamente aos interesses dos setores privados em sua lógica empresarial (DARDOT; LAVAL, 2016; HYPOLITO, 2019). Em concordância com esta análise, a padronização dos currículos e sua relação com exames nacionais, numa concepção de que boa escola é aquela que obtém bons resultados nas avaliações, em geral, censitárias.

Isto posto, à atual Resolução n.o 2, de 20 de dezembro de 2019, que define as Diretrizes Curriculares Nacionais para a Formação Inicial de Professores para a Educação Básica e institui a Base Nacional Comum para a Formação Inicial de Professores da Educação Básica. Estranhamente, é retirada desse texto a formação continuada, o que descaracteriza a formação docente, principalmente na articulação estabelecida na Resolução n. $\stackrel{0}{2}$, de 1.ํㅜ de julho de 2015, entre a formação e 
valorização dos profissionais da educação, destacando à importância da formação continuada dos professores para o seu desenvolvimento profissional.

Essas políticas de formação continuada reafirmam a importância para garantir ao (à) professor (a) as oportunidades efetivas para reflexões sobre a sua prática em seu exercício da docência. E o local onde se dá as suas práticas educativas é a escola, espaço rico e desafiador para os (as) professores (as). Além de possibilitar a articulação constante afora a formação inicial.

Desse modo, a formação continuada centrada na escola busca responder de modo mais profundo às demandas formativas de professores (as) em seu espaço de trabalho, de constantes aprendizagens, peculiaridades e diversidades. Superando um modelo capitalista de formação voltada ao modelo acadêmico, clássico, desenvolvidas por instituições de ensino superior e/ou empresas contratadas.

\section{Considerações Finais}

A reflexão aqui feita sobre a importância da formação continuada centrada na escola permite a aproximação da organização da prática pedagógica e da docência, perpassando pelos elementos que compreende a importância das práticas pedagógicas que constitui o professor (a).

Destacamos enquanto fator importante para a formação continuada centrada na escola e o desenvolvimento das capacidades organizativas das práticas pedagógicas do professor (a), a superação do professor (a) prático utilitário ao se permitir formarse em seu ambiente de trabalho.

Identificamos as aproximações teóricas com os princípios do DPD, mediante referencial teórico utilizado nesta construção reflexiva, que apresentou definições e reflexões das principais referências em DPD e formação continuada para afirmar/justificar a importância da escola como espaço democrático de formação individual e coletiva, de professores(as).

Defendemos essa formação no espaço escolar e com as demandas formativas apontadas pela equipe de professores (as), em parceria e na construção de um diálogo formativo com a universidade, cumprindo com seu papel formador. Defendemos também que essa formação continuada, no espaço da escola, pode se aproximar das 
discussões e princípios do Desenvolvimento Profissional Docente, ampliando as possibilidades de construção e reflexão sobre a carreira docente.

Nesse sentido, a formação continuada centrada na escola proporciona aos professores (as) da Educação Básica uma importante articulação entre suas necessidades e o serviço prestado a comunidade, capacita o professor (a) a desenvolver novas práticas que venham contribuir para o sucesso docente escolar.

\section{Referências}

AZZI, Sandra. Trabalho docente: autonomia didática e construção do saber pedagógico. Saberes pedagógicos e atividade docente, v. 2, p. 35-60, 1999.

BRASIL. Lei 9.394/1996. Lei de Diretrizes e Bases da Educação Nacional. Brasília: Senado Federal: Coordenação de Edições Técnicas, 2017. 58 p.

BRASIL. Lei n. 13.005/2014. Aprova o Plano Nacional de Educação - PNE e dá outras providências. Brasília, DF: Presidência da República, 2014. Disponível em:

http://pne.mec.gov.br/18-planos-subnacionais-de-educacao/543-plano-nacional-deeducacao-lei-n-13-005-2014. Acesso em: 28 maio 2020.

BRASIL. Ministério da Educação. Conselho Nacional De Educação. Resolução $n^{\circ}$ 2, de $1^{\circ}$ de julho de 2015. Define as Diretrizes Curriculares Nacionais para a formação inicial em nível superior (cursos de licenciatura, cursos de formação pedagógica para graduados e cursos de segunda licenciatura) e para a formação continuada. Brasília: Ministério da Educação, 2015. Disponível em: http://portal.mec.gov.br/docman/agosto-2017-pdf/70431-res-cne-cp-00203072015-pdf/file Acesso em: 28 maio 2020.

BRASIL. Ministério da Educação. Conselho Nacional De Educação. Resolução CNE/CP $n$ o 2, de 20 de dezembro de 2019. Define as Diretrizes Curriculares Nacionais para a Formação Inicial de Professores para a Educação Básica e institui a Base Nacional Comum para a Formação Inicial de Professores da Educação Básica (BNC-Formação). Brasília: Ministério da Educação, 2019.

CARVALHO, Anna Maria Pessoa de; GIL-PÉREZ, Daniel. Formação de professores de ciências: tendências e inovações. São Paulo: Cortez, 2011.

CUNHA, Renata Cristina Oliveira Barrichelo; PRADO, Guilherme do Val Toledo. Formação centrada na escola, desenvolvimento pessoal e profissional de professores. Revista de Educação PUC-Campinas, Campinas, n. 28, p.101-111, jan./jun. 2010.

DARLING-HAMMOND, Linda. A importância da formação docente. Cadernos Cenpec, São Paulo, n. 2, v. 4, p.1-18, jun. 2015.

DARLING-HAMMOND, Linda; HYLER, Maria E.; GARDNER, Madelyn. Effective teacher professional development. Palo Alto: Learning Policy Institute, 2017. 
DARLING-HAMMOND, Linda. Lo que necesitan conocer y saber hacer los profesores. In: DELGADO, Juan Arturo Padilha et al. (comp.). Educação Física III: antologia. Argentina: Secretaría de Educación Pública, 2008. p. 25-28.

FERREIRA, Lúcia Gracia. Desenvolvimento profissional docente: percursos teóricos, perspectivas e (des)continuidades. Educação Em Perspectiva, Viçosa, v. 11, 2020. Disponível em: https://doi.org/10.22294/eduper/ppge/ufv.v11i.9326. Acesso em: 7 maio 2020.

FREIRE, Paulo. Educação e atualidade brasileira. 3. ed. São Paulo: Cortez: Instituto Paulo Freire, 2004.

FREIRE, Paulo. Pedagogia da autonomia: saberes necessários à prática educativa. 19. ed. São Paulo: Paz e Terra, 1996.

FREITAS, Helena Costa Lopes de. CNE ignora entidades da área e aprova Parecer e Resolução sobre BNC da Formação. Blog da Helena.[S. l.], 7 nov. 2019. Disponível em: https://formacaoprofessor.com/2019/11/07/cne-ignora-entidades-da-area-eaprova-resolucao-sobre-bnc-daformacao/\#: :text=0\%20Conselho\%20Pleno $\% 20 \mathrm{e} \% 20 \mathrm{a}$,Comum $\% 20 \mathrm{de} \% 20$ Forma \%C3\%A7\%C3\%A3o\%20Inicial\%20de. Acesso em: 7 maio 2020.

GARCIA, Carlos Marcelo. Formação de professores para uma mudança educativa. Porto: Porto Editora, 1999.

GATTI, Bernardete Angelina. Políticas educacionais e educação básica: desafios para as políticas e formação docente. In: PACHECO RIOS, J. A. V. (org.). Políticas, práticas e formação na educação básica. Salvador: Editora da UFBA, 2015. p. 25-34.

GATTI, Bernardete Angelina; BARRETTO, Elba Siqueira de Sá; ANDRÉ, Marli Eliza Dalmazo de Afonso. Políticas docentes no Brasil: um estado da arte. 12. ed. Brasília: Unesco, 2011.

GATTI, Bernadete A. Formação de professores no Brasil: características e problemas. Educação e Sociedade, Campinas, v. 31, n. 113, p. 1355-1379, out./dez. 2010.

GATTI, Bernadete Angelina. A construção metodológica da pesquisa em educação: desafios. Revista Brasileira de Política e Administração da Educação-Periódico científico, Brasília, v. 28, n. 1, 2012.

IMBERNÓN, Francisco. Formação continuada de professores. Porto Alegre: Artmed, 2010.

IMBERNÓN, Francisco. Formação docente e profissional: forma-se para a mudança e a incerteza. São Paulo: Cortez, 2002.

LIBÂNEO, José Carlos. Formação de professores e didática para desenvolvimento humano. Educação \& Realidade, Porto Alegre, v. 40, n. 2, p. 629-450, 2015. 
MARCELO GARCIA, Carlos. Desenvolvimento profissional docente: passado e futuro. Sísifo: Revista de Ciências da Educação, Sevilha, v. 8, p. 7-22, jan./abr. 2009.

MIZUKAMI, Maria da Graça Nicoletti. Escola e desenvolvimento profissional da docência. In: GATTI, B. A.; SILVA JÚNIOR, A. C.; PAGOTTO, M. D. S.; NICOLETTI, M. G. (org.). Por uma política nacional de formação de professores. São Paulo: Editora Unesp, 2013. p. 23-54.

NÓVOA, António. Formação de professores e profissão docente. Porto: Porto Editora, 1992.

PIMENTA, Selma Garrido. Organização saberes pedagógicos e atividades docentes. São Paulo: Cortez, 1999.

PIMENTA, Selma Garrido; GHEDIN, Evandro. (org.). Professor reflexivo no Brasil: gênese e crítica de um conceito. 2. ed. São Paulo: Cortez, 2002.

PIMENTA, Maria Socorro Lucena; PIMENTA, Selma Garrido. Estágio e docência. São Paulo: Cortez, 2004.

RIBEIRO, Andréa; SEDANO, Luciana. Formação docente: o perfil dos professores de ciências dos anos finais do ensino fundamental. Revista Prática Docente, Confresa, v. 5, n. 2, p. 1234-1255, 2020.

SILVA, Andréa Ribeiro; DE SOUZA, Luciana Sedano. Currículo e desenvolvimento profissional docente: um olhar sobre uma proposta de formação continuada. Linguagens, Educação e Sociedade, Teresina, v. 1518, p. 323-360, 2018.

VAILLANT, Denise; MARCELO, Carlos. Desenvolvimento profissional docente. In: VAILLANT, Denise; MARCELO, Carlos. Ensinando a ensinar: as quatro etapas de uma aprendizagem. Curitiba: UTFPR, 2012. p. 165-181.

WEI, Ruth Chung et al. Professional learning in the learning profession: a status report on teacher development in the united states and abroad. Washington DC: National Staff Development Council, 2009. 